\title{
Bilirubin accumulation and Cyp mRNA expression in selected brain regions of jaundiced Gunn rat pups
}

\author{
Silvia Gazzin', Jaroslav Zelenka², Lucie Zdrahalova² ${ }^{2}$ Renata Konickova², Carlos Coda Zabetta', Pablo J. Giraudi', \\ Andrea L. Berengeno' ${ }^{1}$, Alan Raseni ${ }^{3}$, Maria C. Robert ${ }^{1}$, Libor Vitek ${ }^{4}$, and Claudio Tiribelli ${ }^{5}$
}

INTRODUCTION: Few data exist on regional brain bilirubin content in the neonatal period when acute bilirubin-induced neurologic damage (BIND) may occur, and no information is available on regional brain expression of cytochrome P450 monooxygenases (Cyps) that oxidize bilirubin.

METHODS: Bilirubin content was analyzed by high-performance liquid chromatography and Cyp1a1, 1a2, and 2a3 mRNA expression was analyzed by quantitative PCR (qPCR) in cortex (Cx), cerebellum (CII), superior colliculi (SC), and inferior colliculi (IC) of 17-d-old hyperbilirubinemic (jj) Gunn rat pups before and after administration of sulphadimethoxine to acutely displace bilirubin from plasma albumin.

RESULTS:Therewas no difference in bilirubin contentamong brain regions in untreated rats. After intraperitoneal sulphadimethoxine, bilirubin content peaked at fourfold in Cx and SC at $1 \mathrm{~h}$; but at 11to 13 -fold in Cll and IC at 24h; returning to control levels at $72 \mathrm{~h}$. The Cyp mRNA peaked at 30-70 times control at $1 \mathrm{~h}$ in Cx and SC, but at 3-9 times control at 24h in CII and IC.

DISCUSSION: The close relationship in distinct brain regions between the extent of bilirubin accumulation and induction of mRNA of Cyps suggests Cyps may have a role in protecting selected brain areas from bilirubin neurotoxicity.

A lthough physiological neonatal jaundice is believed to protect newborns against oxidative stress (1), severe unconjugated hyperbilirubinemia may cause irreversible bilirubin-induced neurologic damage (BIND) (2). Recent findings emphasize that diffusion of unconjugated bilirubin (UCB) into cells, causing neurotoxicity, is related to the unbound, free fraction of plasma UCB (Bf), rather than the total plasma UCB level (3-5).

Visible staining with UCB in the basal ganglia of both newborn babies who died from extreme hyperbilirubinemia and of jaundiced Gunn rats (the classic animal model of neonatal hyperbilirubinemia and Crigler-Najjar type I syndrome) after a bilirubin load (6-8) is called "kernicterus." However, there are very few reports in humans that strictly describe such selective bilirubin accumulation in specific brain regions (9). Similarly, kernicterus in experimental animals seems to occur only under extreme conditions, e.g., when agents acutely displacing UCB from albumin engender a sudden entry of UCB into the central nervous system. Moreover, previous studies utilized poor analytical methods to document the increases in brain UCB content, so that they were limited to these experimental conditions $(6,7)$.

The first aim of this work was to apply a sensitive, specific high-performance liquid chromatography method (10) to assess tissue UCB levels spontaneously present in Gunn (ji) rats with jaundice due to a homozygous mutation, leading to loss of function of bilirubin-UDP glucuronosyl transferase (UGT1A1), and their heterozygous (Jj) and wild-type (JJ) littermates. The second aim was to study serial changes in regional brain UCB levels when $\mathrm{jj}$ Gunn rats were treated with sulphadimethoxine to acutely displace UCB from albumin, mimicking the effects of acute increases in unconjugated hyperbilirubinemia that can occur in jaundiced newborns and patients with Crigler-Najjar type I.

Hyperbilirubinemic Gunn rats partially compensate for their inability to conjugate UCB by its oxidation catalyzed by hepatic cytochrome P450 monooxygenases (Cyps) 1a1, 1a2 (11-13), and 2a3 (Cyp2a5 in humans) (14). Export of UCB by two ATP-binding cassette transporters (ABCc1 and $\mathrm{ABCb} 1$ ) has a role in protecting cultured central nervous system cells from UCB toxicity (15-19). Therefore, the mRNA expression of the three Cyps and two $\mathrm{ABC}$ transporters was assessed in selected brain regions by quantitative PCR (qPCR).

\section{RESULTS}

\section{Total Bilirubin and Albumin in Plasma}

As expected (Table 1), the jj rats had much higher plasma bilirubin concentrations at all postnatal ages as compared with both $\mathrm{JJ}$ and $\mathrm{Jj}$ animals $(P<0.001)$. In $\mathrm{jj}$ animals, the bilirubin concentration peaked at day $9(\mathrm{~d} 9$; around $250 \mu \mathrm{mol} / \mathrm{l})$, remained comparable until $\mathrm{d} 17$, and then decreased to about $80 \mu \mathrm{mol} / \mathrm{l}$ at $\mathrm{d} 60$ (d60 jj vs. d2, d9, and d17 jj: $P<0.01$ ). In heterozygous Jj Gunn rats, plasma bilirubin concentrations at $\mathrm{d} 2$ and $\mathrm{d} 9$ were 9 - and 13 -fold higher, respectively, than in

\footnotetext{
The first two authors contributed equally to this work.

${ }^{1}$ Fondazione Italiana Fegato (Italian Liver Foundation), Trieste, Italy; ${ }^{2}$ Institute of Clinical Biochemistry and Laboratory Diagnostics, 1 st Faculty of Medicine, Charles University,

Prague, Czech Republic; ${ }^{3}$ S.C. Laboratorio Analisi Cliniche, IRCCS Burlo Garofolo, Trieste, Italy; ${ }^{4}$ Department of Internal Medicine, 1 st Faculty of Medicine, Charles University, Prague, Czech Republic; ${ }^{5}$ Department of Medical Sciences, 1st Faculty of Medicine, Charles University, Prague, Czech Republic. Correspondence: Silvia Gazzin (silvia.gazzin@csf.units.it)
} 
Table 1. Postnatal changes in plasma bilirubin and albumin in Gunn rats

\begin{tabular}{lcccccccccc}
\hline & & TBil $(\mu \mathrm{mol} / \mathrm{l})$ & & \multicolumn{3}{c}{ Albumin $(\mu \mathrm{mol} / \mathrm{l})$} & \multicolumn{2}{c}{ B/A ratio } \\
\hline & $\mathrm{J}$ & $\mathrm{Jj}$ & $\mathrm{j}$ & $\mathrm{J}$ & $\mathrm{Jj}$ & $\mathrm{jj}$ & $\mathrm{J}$ & $\mathrm{Jj}$ & $\mathrm{jj}$ \\
\hline $\mathrm{d} 2$ & $7.3 \pm 1.5$ & $66.6 \pm 23.4$ & $234.5 \pm 33$ & $178 \pm 84.2$ & $182.4 \pm 69$ & $178.6 \pm 66$ & 0.04 & 0.36 & 1.31 \\
$\mathrm{~d} 9$ & $6.3 \pm 1.0$ & $82.3 \pm 21.0$ & $247.8 \pm 26$ & $238.6 \pm 77.6$ & $245.1 \pm 77.8$ & $230 \pm 85.1$ & 0.03 & 0.33 & 1.08 \\
$\mathrm{~d} 17$ & $5.7 \pm 1.5$ & $6.9 \pm 3.8$ & $231.2 \pm 57$ & $432.5 \pm 83.9$ & $456.7 \pm 40.2$ & $420.8 \pm 75.6$ & 0.01 & 0.015 & 0.55 \\
$\mathrm{~d} 60$ & $3.2 \pm 0.9$ & $3.1 \pm 1.0$ & $82.1 \pm 8.7$ & $591.3 \pm 20.35$ & $607.5 \pm 32.5$ & $581.1 \pm 38.3$ & 0.005 & 0.005 & 0.14 \\
\hline
\end{tabular}

B/A ratio, plasma bilirubin/albumin molar ratio; d, postnatal day; JJ, wild-type; Jj, heterozygous; jj, homozygous recessive; TBil, total bilirubin in plasma.

age-matched $\mathrm{JJ}$ animals $(P<0.001)$, but decreased to levels comparable with JJ animals at d17. In JJ animals, plasma bilirubin levels remained low and constant from $\mathrm{d} 2$ to adulthood.

Plasma albumin levels increased significantly from $\mathrm{d} 2$ to adulthood $(P<0.01$, Table 1$)$, without differences among genotypes.

In both JJ and Jj animals, during the whole postnatal period, the plasma bilirubin/albumin molar ratio (B/A) was below 0.6, the cutoff value for increased risk of bilirubin neurotoxicity (20). In contrast, in hyperbilirubinemic $\mathrm{jj}$ rats, the ratio was clearly $>1$ at $\mathrm{d} 2$ and at $\mathrm{d} 9$, declining to 0.55 at $\mathrm{d} 17$. At $\mathrm{d} 60$, the $\mathrm{B} / \mathrm{A}$ ratio in $\mathrm{jj}$ rats was within a safe range (Table 1 ).

\section{Organ UCB Levels in Untreated Gunn Rat Pups at d9 and d17}

In $\mathrm{jj}$ Gunn rats, at both ages, UCB content in the liver was almost 10 times that of the brain, with intermediate levels in spleen and kidneys, and was significantly greater than in the same organs of $\mathrm{Jj}$ and $\mathrm{JJ}$ rats (Figure 1).

During development, the organ bilirubin content significantly decreased (by 37-66\%) in liver, kidney, and brain of JJ and $\mathrm{Jj}$ rats, whereas no statistically significant changes were detected in the same organs of $\mathrm{jj}$ animals. Splenic bilirubin content increased significantly with age in jj Gunn rats but did not change in normobilirubinemic animals (Figure 1).

\section{Tissue Bilirubin in Selected Brain Regions of Gunn Pups and Effect of Sulphadimethoxine}

No differences were detected in UCB content among the four brain regions in the jj rat strain (Figure 2a); this was true also in $\mathrm{Jj}$ and JJ pups (data not shown). Despite the similar tissue UCB contents in cortex $(\mathrm{Cx})$ and cerebellum (Cll) of $\mathrm{jj}$ animals, a relevant cerebellar hypotrophy was detected in $\mathrm{jj}$ animals starting from $\mathrm{d} 9(P<0.01)$ and becoming even more drastic at $\mathrm{d} 17$ $(P<0.01)$ (Figure $2 \mathrm{~b})$; $\mathrm{Cx}$ growth was unaffected.

As shown in Figure 3a, the plasma bilirubin level plummeted $90 \%$ by $60 \mathrm{~min}$ after sulphadimethoxine administration and rose to almost $70 \%$ of the original value after $6 \mathrm{~h}$, but took more than $48 \mathrm{~h}$ to return to pretreatment levels. This was associated with accumulation of bilirubin in the brain, but the timing and the extent of UCB deposition greatly varied in the different regions explored (Figure $3 \mathrm{~b}-\mathrm{e}$ ). In the (b) $\mathrm{Cx}$ and (c) superior colliculi (SC), a fourfold increase was observed at $60 \mathrm{~min}$, which then slowly and progressively decreased to or below pretreatment values at $72 \mathrm{~h}$. Bilirubin deposition in the (d) Cll differed markedly, with an 11 -fold increase at $6 \mathrm{~h}$ that lasted to $24 \mathrm{~h}$ and then declined
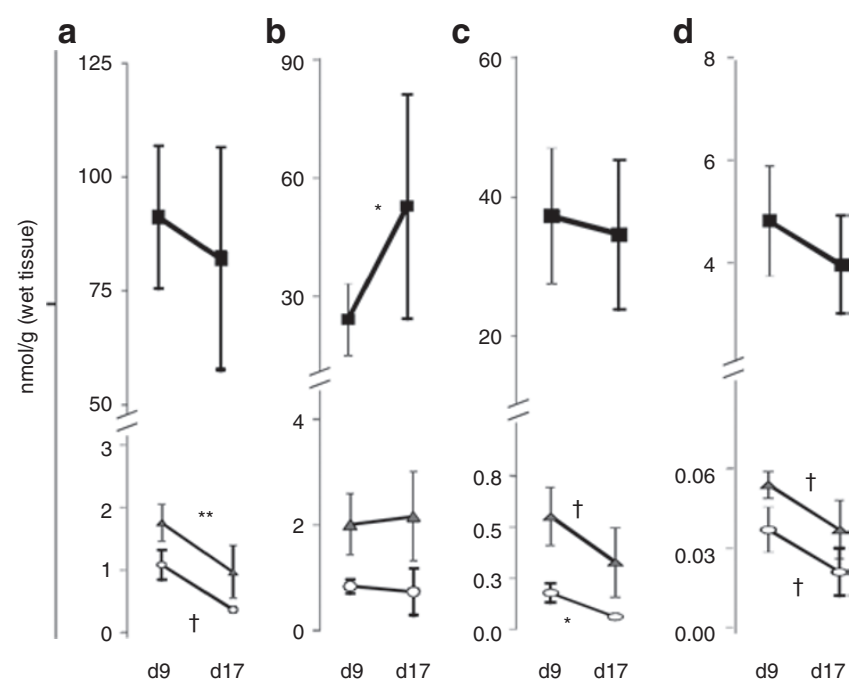

Figure 1. Tissue UCB content in abdominal organs and brain of Gunn rats. d: postnatal age (in days). Filled squares, hyperbilirubinemic jj; filled triangles, heterozygous Jj; and open circles, wild-type JJ Gunn rats.

(a) Liver; (b) spleen; (c) kidney; and (d) brain. ${ }^{*} P \leq 0.05$; ${ }^{* *} P \leq 0.01$; ${ }^{+} P \leq 0.005$. Not statistically significant if not indicated. UCB, unconjugated bilirubin.
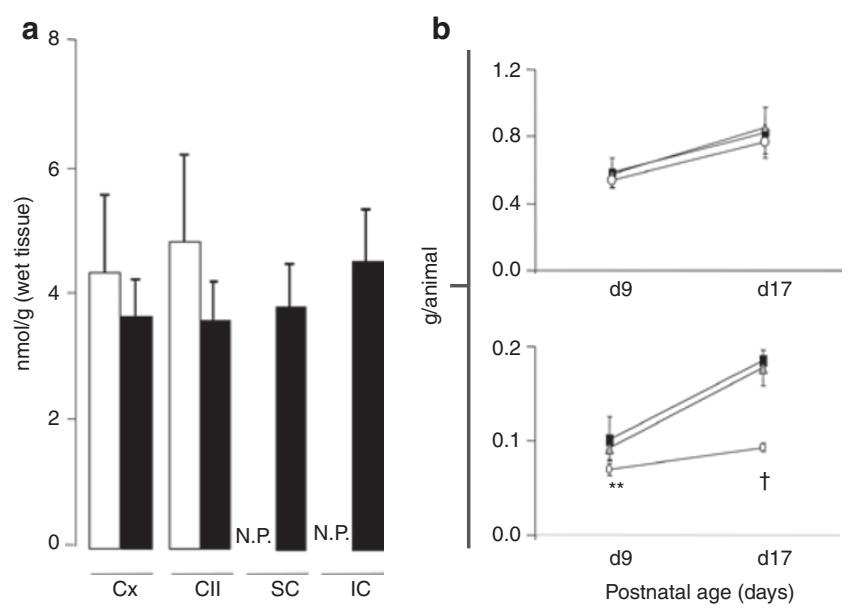

Figure 2. Data on brain regions of untreated, jaundiced jj Gunn rats. (a) Tissue UCB content in selected brain regions. White bars: day 9 (d9); black bars: d17. (b) Wet weight of cortex (above) and Cll (below). Filled squares, hyperbilirubinemic jj; filled triangles, heterozygous $\mathrm{Jj}$; and open circles, wild-type JJ Gunn rats. ${ }^{* *} P \leq 0.01 ;{ }^{+} P \leq 0.005$. Other differences not statistically significant. Cll, cerebellum; CX, cerebral cortex; IC, inferior collicula; N.P., not performed; SC, superior collicula; UCB, unconjugated bilirubin. 

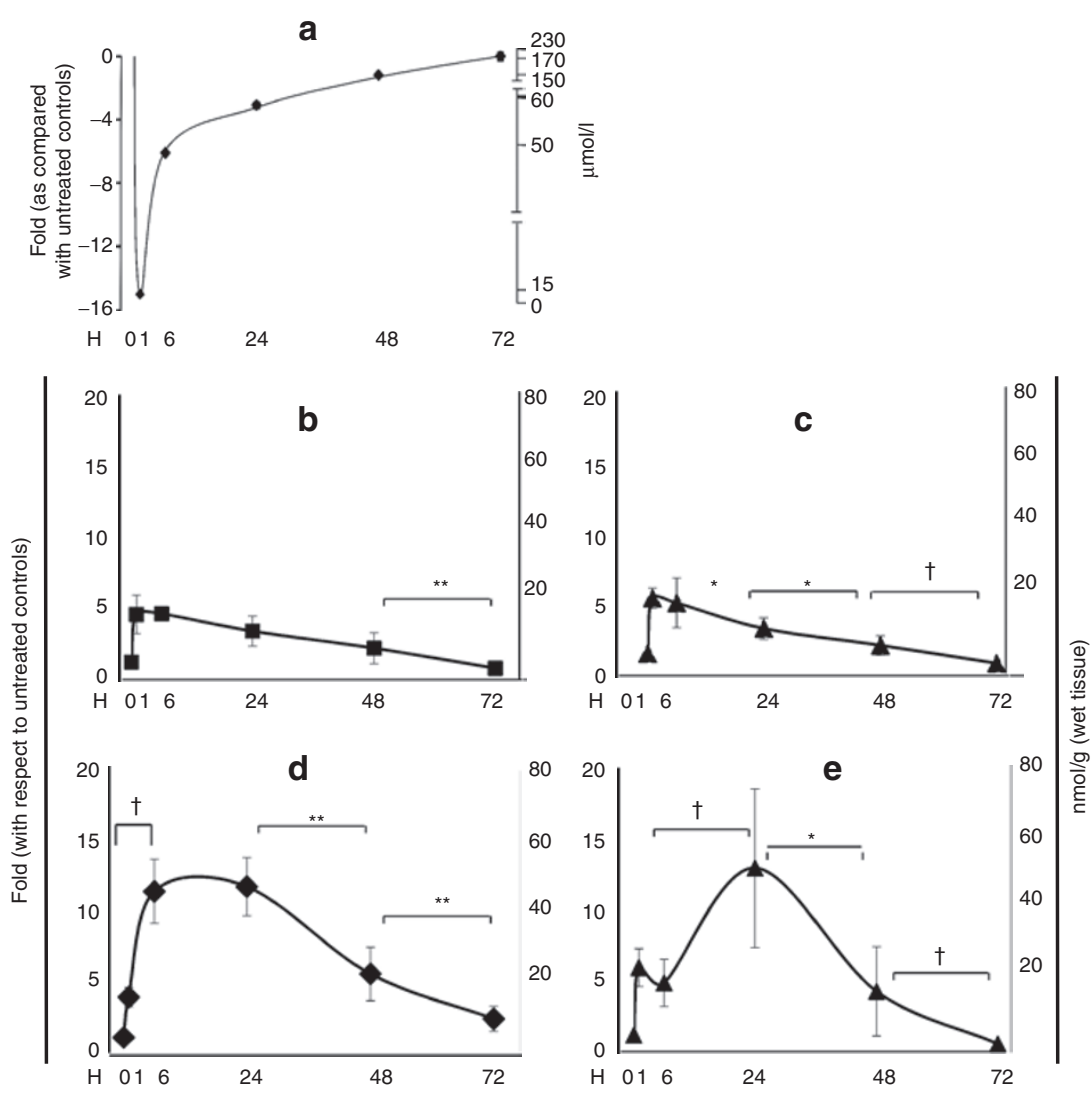

Figure 3. UCB levels in (a) plasma and (b-e) selected brain regions of day $17 \mathrm{jj}$ Gunn rats after sulphadimethoxine exposure. (b) Cerebral cortex, (c) superior collicula, (d) cerebellum, and (e) inferior collicula. ${ }^{*} P \leq 0.05 ;{ }^{* *} P \leq 0.01 ;{ }^{\dagger} P \leq 0.005$. Other differences not statistically significant. The UCB content of each cerebral region of sulphadimethoxine-exposed $\mathrm{jj}$ rat is expressed as the ratio to the UCB content in the same region of vehicle-treated $\mathrm{jj}$ littermate (control). $\mathrm{H}$, hours after sulphadimethoxine exposure; UCB, unconjugated bilirubin.

slowly to twofold baseline levels at $72 \mathrm{~h}$. In the (e) inferior colliculi (IC), the peak of bilirubin content (13-fold of baseline) was reached at $24 \mathrm{~h}$ and returned to pretreatment values at $72 \mathrm{~h}$.

\section{Effects of Sulphadimethoxine on Expression of Cyps in Brain Regions of $\mathrm{d} 17 \mathrm{jj}$ Rats}

Similar patterns of mRNA expression of Cyp1a1, Cyp1a2, and Cyp2a3 isoforms were detected in brains of sulphadimethoxineexposed rats (Figure 4). In the $\mathrm{Cx}$, a strong increase (25- to 70-fold as compared with unexposed, control jj littermates) was observed at 1 and $6 \mathrm{~h}$, decreasing from 24 to $72 \mathrm{~h}$ to levels similar to those of unexposed littermates. A similar kinetics was also observed in the SC, where Cyp mRNAs were upregulated 20 - to 45 -fold after $1 \mathrm{~h}$, dropping thereafter to or below pretreatment levels.

In sharp contrast, the $\mathrm{Cll}$ and IC exhibited a delayed and less pronounced response to sulpha. Cyp mRNAs were unchanged at 1 and $6 \mathrm{~h}$, but at $24 \mathrm{~h}$ peaked at 3-5 times controls in the Cll and 5-9 times controls in the IC; levels in both regions declined gradually to normal levels at $72 \mathrm{~h}$.

Effects of Sulphadimethoxine on Expression of ABCs in Brain Regions of $\mathrm{d} 17 \mathrm{jj}$ Rats

Only slight modulation of $A B C c 1$ and $A B C b 1$ occurred after sulphadimethoxine treatment (Figure 5). In $\mathrm{Cx}, A B C c 1$
mRNA was unchanged, whereas $A B C b 1$ expression increased threefold at 1 and $6 \mathrm{~h}$, slowly decreasing to control levels by $72 \mathrm{~h}$. In SC, expression of both $A B C c 1$ and $A B C b 1$ displayed similar three- to fourfold upregulation at 1 and $6 \mathrm{~h}$, then gradually declined to or below control levels at $72 \mathrm{~h}$. In Cll, $A B C c 1$ mRNA gradually increased from 1 to $48 \mathrm{~h}$, then declined to control levels at $72 \mathrm{~h}$; by contrast, $A B C b 1$ peaked with similar intensity at $24 \mathrm{~h}$. In IC, both transporter mRNAs attained maximal expression after $1 \mathrm{~h}$, then returned to control levels from $6 \mathrm{~h}$ on.

Sulphadimethoxine itself did not affect the expression of any Cyp isoenzymes or ABC transporters in the nonjaundiced JJ rats (Figure 6).

\section{DISCUSSION}

Only the unbound fraction of UCB (Bf) can enter tissues. This process becomes clinically relevant when the load of bilirubin is excessive or when agents competitively displace UCB from binding sites on albumin $(3,5)$. Because of multiple factors affecting $\mathrm{UCB}$ binding and $\mathrm{Bf}$, it has not been possible to define a bilirubin/albumin molar ratio (B/A) considered to be safe in protecting against $\mathrm{BIND}$. In humans, at $\mathrm{B} / \mathrm{A} \geq 0.7$ in blood, irreversible neurological damage often occurs, whereas at $\mathrm{B} / \mathrm{A}$ $\geq 0.6$, it is usually reversible (20). In vitro studies suggest that cultured central nervous system cells may suffer UCB toxicity 
a

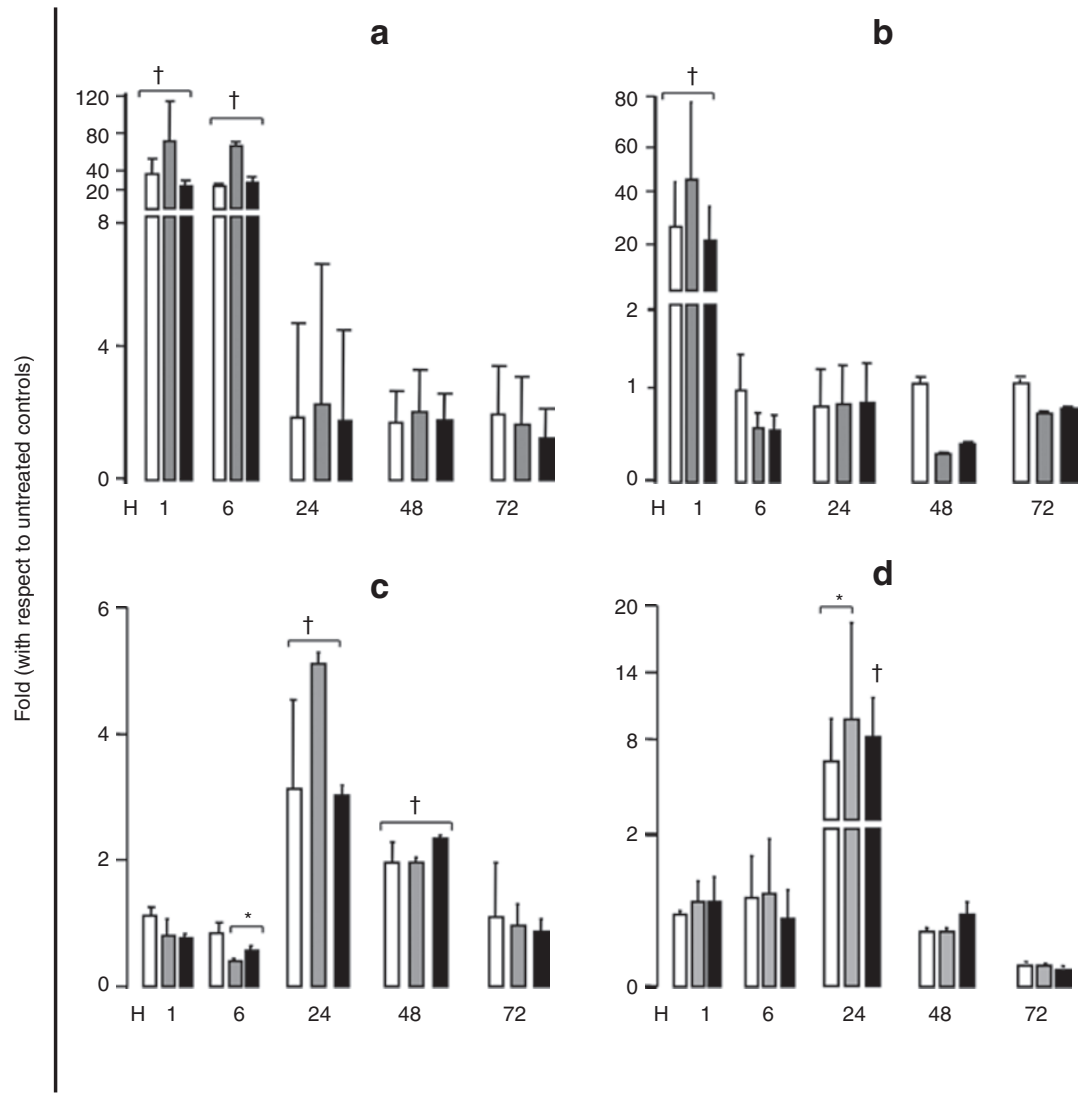

Figure 4. Cyp mRNA expression in selected brain regions of day $17 \mathrm{jj}$ Gunn rats after sulphadimethoxine exposure. (a) Cerebral cortex, (b) superior collicula, (c) cerebellum, and (d) inferior collicula. ${ }^{*} P \leq 0.05 ;{ }^{\dagger} P \leq 0.005$. Other differences not statistically significant. White bars, Cyp 1a 1; gray bars, Cyp 1a2; and black bars, Cyp2a3 mRNA expression. Cyp, cytochrome P450 monooxygenase; $\mathrm{H}$, hours after sulphadimethoxine exposure.

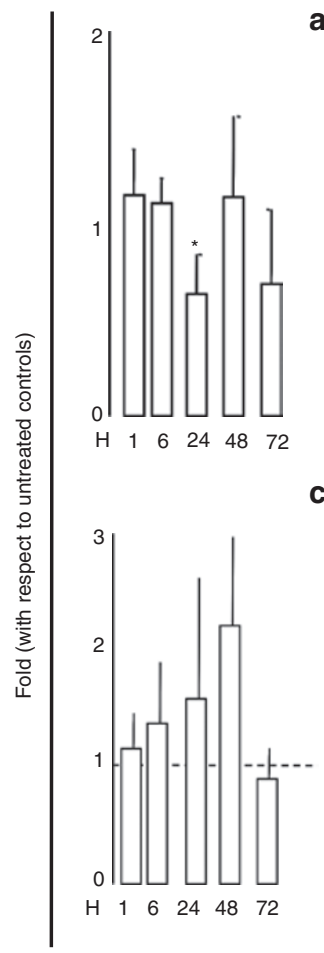

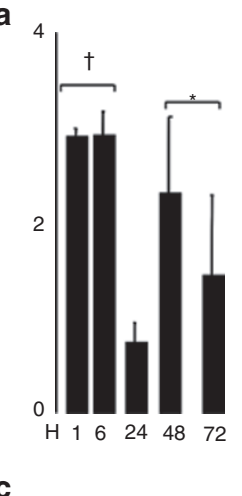

C

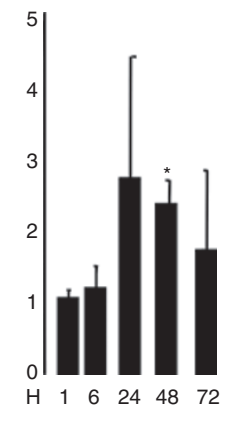

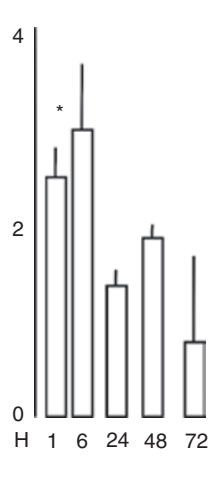

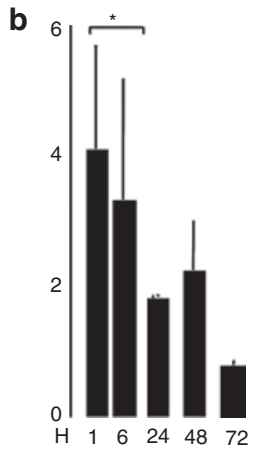

d
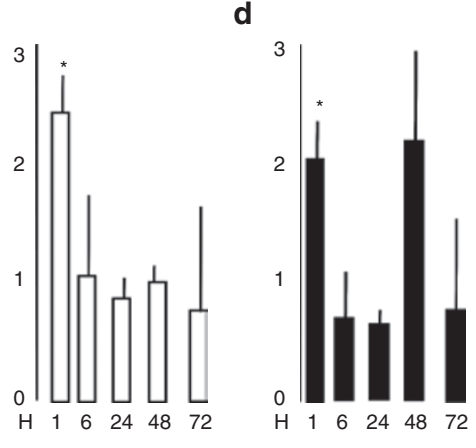

Figure 5. $A B C$ mRNA expression in selected brain regions of day $17 \mathrm{jj}$ Gunn rats after sulphadimethoxine exposure. (a) Cerebral cortex, (b) superior collicula, (c) cerebellum, and (d) inferior collicula. ${ }^{*} P \leq 0.05 ;{ }^{\dagger} P \leq 0.005$. Other differences not statistically significant. White bars, $A B C c 1 ;$ black bars, $A B C b 1$ mRNA expression. $\mathrm{H}$, hours after sulphadimethoxine exposure. 


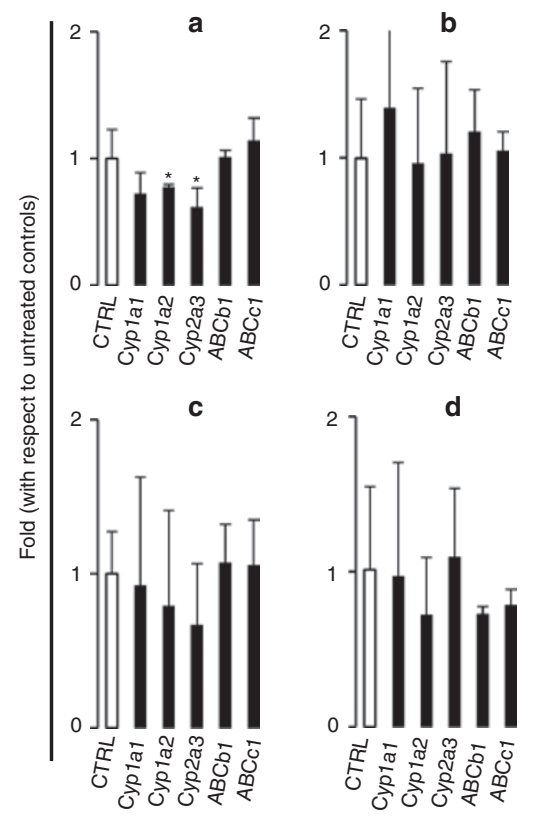

Figure 6. Cyp and $A B C$ mRNA modulation by sulphadimethoxine in selected brain regions of day $17 \mathrm{JJ}$ Gunn rats. (a) Cerebral cortex, (b) superior collicula, (c) cerebellum, and (d) inferior collicula. ${ }^{*} P \leq 0.05$. Other differences not statistically significant. White bars, controls (vehicle-injected animals) and black bars, sulpha-treated rats. Cyp, cytochrome P450 monooxygenase.

at even lower ratios $(<0.5)(3,21,22)$, but caution is advised in extrapolation of the in vitro data to the much more complicated situation in vivo.

Hyperbilirubinemia in jj Gunn rats results from a deficiency of hepatic UGT1A1, similar to that seen in human patients with Crigler-Najjar type I and analogous to the decreased conjugating activity seen in human neonates during the first days of life (23). As in severely jaundiced newborns, the high levels of UCB in plasma of $\mathrm{jj}$ Gunn rat pups, with B/A ratios exceeding 1.0 at $\mathrm{d} 2$ and $\mathrm{d} 9$, resulted in accumulation of UCB in the tissues in the early neonatal period; in jj Gunn pups, this causes marked cerebellar hypotrophy from $\mathrm{d} 9$ onward $(24,25)$. In heterozygous ( $\mathrm{Jj}$ ) Gunn rats, the milder, early, temporary hyperbilirubinemia did not impair cerebellar growth, suggesting that the $0.36 \mathrm{~B} / \mathrm{A}$ ratio found at $\mathrm{d} 2$ may be safe. It is interesting that $\mathrm{d} 2$ jj rats showed no signs of bilirubin toxicity $(4,25)$, suggesting that it takes time for UCB to accumulate in the central nervous system and/or for neurotoxicity to develop.

In jj Gunn rats, we found UCB content to be higher in liver than in spleen and kidneys, and much lower in whole brain (Figure 1). As reported in humans (20), visceral bilirubin concentrations decreased less rapidly than plasma bilirubin levels from $\mathrm{d} 9$ to $\mathrm{d} 17$, whereas brain UCB content declined more rapidly (24\%) than plasma bilirubin levels (6.5\%) during the same period. The decline of UCB content in all organs is likely in part related to the large increase in plasma albumin from $\mathrm{d} 9$ to $\mathrm{d} 17$, enhancing the decrease in plasma $\mathrm{B} / \mathrm{A}$ ratio and $\mathrm{Bf}$ concentration as total plasma UCB levels decline. This is consistent with previous reports of lower bilirubin concentrations in liver, spleen, kidney, and whole brain of adult Gunn rats than in pups (26).
The differences in UCB content and rates of decline among the organs (Figure 1) indicate, however, that tissue UCB levels must also be controlled by other mechanisms. The production rates of UCB in the organ and the permeability to UCB of the blood-organ barriers (10) determine the supply of UCB. Because Gunn (jj) rats cannot conjugate bilirubin, the cellular export of UCB $(15,16,18,19)$ and UCB oxidation $(12,14,26-28)$ might play a role in UCB removal from the brain of these animals.

Our study in jj rats after sulphadimethoxine administration provides important new data on the time dependency of the consequent sudden, massive accumulation and gradual clearance of UCB in different brain regions (Figure $3 b-e$ ). Notable are the much greater and longer-lasting accumulations of UCB in the Cll and IC, whose functions (motor coordination and auditory, respectively) are impaired in bilirubin encephalopathy of sudden onset after sulphadimethoxine administration (29), and the more gradual onset in jaundiced neonates and jj Gunn rats. By contrast, UCB accumulation after sulphadimethoxine was limited and brief in the $\mathrm{Cx}$ and IC, whose functions (cognition and vision, respectively) are unimpaired in BIND. The spatial nearness of the SC and IC suggest further that their markedly different kinetics and severity of UCB accumulation after sulphadimethoxine are unlikely to be due to differences blood supply or blood-brain barriers, but most probably are linked to cellular mechanisms for removal of UCB.

This conclusion is further supported by the relationships between expression of Cyps known to oxidize UCB and the dynamics of tissue UCB in the selected brain regions. Figures 4 and 5 show an immediate and massive upregulation of the Cyp mRNAs and much smaller immediate upregulation of the $\mathrm{ABC}$ transporters in the unaffected brain regions ( $\mathrm{Cx}$ and $\mathrm{SC}$ ), in striking contrast to the delayed and relatively puny upregulation of Cyps and $\mathrm{ABC}$ transporters in the affected brain regions (Cll and IC). The timing seems to fit with the decline in tissue UCB levels after $1 \mathrm{~h}$ in the unaffected regions but only after $6 \mathrm{~h}$ in the affected regions (Figure 4). This suggests that these Cyps (and, presumably, UCB oxidation) provide major protection against acute accumulation of UCB in the unaffected regions, with the ABC transporters playing a minor role. Because only mRNA expression was assessed, confirmation of this hypothesis will require further studies of upregulation of enzyme and transporter protein levels and activities. It needs to be determined also if similar, differential, short-term upregulation of Cyps is stimulated by the relatively rapid, albeit less massive and precipitous, spontaneous increases in brain UCB content during the week after birth in untreated jj Gunn pups

The similarity of increments in tissue UCB levels $1 \mathrm{~h}$ after sulpha administration suggests that there are similar rates of passive diffusion of UCB in all four brain regions during this early accumulation of UCB. Selective upregulation of Cyps, enhancing UCB oxidation, more likely accounts for the subsequent decline in tissue UCB levels. Based on this reasoning, we speculate that limited passive diffusion 
across the blood-brain and blood-cerebrospinal fluid barriers, rather than oxidation or export of UCB, is also the dominant factor determining the similarity of UCB content observed among the four brain regions of untreated jj Gunn rats at $\mathrm{d} 17$ (Figure 2). The reasons why the upregulation differs among different portions of the brain need to be further investigated.

Our data suggest that the historical concept of kernicterus, based on selective damage due to regional bilirubin accumulation in the brain, should be reassessed. Our study shows that regional modulation of Cyps may account for the differences among brain regions in severity and duration of bilirubin accumulation during sudden increases in Bf. It remains to be determined whether BIND in jaundiced Gunn rat pups and neonates is similarly influenced by modulation of intracellular defensive mechanisms, such as oxidation of UCB.

\section{METHODS}

\section{Animals}

Hyperbilirubinemic Gunn rats (jj) (30) with congenital deficiency of UGT1A1 (23) and their heterozygous ( $\mathrm{jj}$ ) and normobilirubinemic wild-type (JJ) littermates (31) were bred in the animal facility of the CSPA, University of Trieste. Parturitions were synchronized to obtain a sufficient number of littermate pups of each genotype and postnatal age $(\mathrm{d} \pm 1)$.

Animal care and procedures were conducted according to the guidelines approved by Italian Law (decree 116-92) and by European
Community directive $86-609-E E C$. The study was approved by the animal care and use committee of the University of Trieste.

\section{Experimental Plan}

Scheme A: Tissue bilirubin contents in untreated jj, Jj, and JJ Gunn rat pups (Figure 7a). Based on previous reports $(6,24,25,32)$, six pups were studied at each of two postnatal ages: $d 9$, when cerebellar growth arrests, and d17, when plasma UCB levels begin to decline. Tissue bilirubin was analyzed in organs involved in heme catabolism or affected by bilirubin toxicity.

Scheme B: Regional brain UCB content in $117 \mathrm{jj}$ Gunn rat pups given sulphadimethoxine (Figure $7 \mathrm{~b}$ ). As described by others $(6,8)$, sulphadimethoxine $(200 \mathrm{mg} / \mathrm{kg}, 3 \mathrm{mg} / \mathrm{ml}$ in phosphate-buffered saline) was injected intraperitoneally to displace UCB from plasma albumin and acutely shift UCB (as Bf) from blood to brain. After isofluorane anesthesia, and the first blood sample collection, the animals were administered sulphadimethoxine solution (sulpha) or an equal volume of phosphate-buffered saline (controls), and all pups returned to the wet-nurse. Six (jj) pups each were killed at 1, 6, 24, 48, and $72 \mathrm{~h}$ after sulpha administration, and blood and four selected brain regions were analyzed for UCB content.

\section{Animal Sacrifice and Sample Collection}

Under deep urethane anesthesia (1.0-1.2 g/ kg intraperitoneally.), a heparinized blood sample was collected by jugular puncture. To minimize contamination of tissues with UCB in blood, the animals were immediately perfused (10) through the incanulated heart left

a \begin{tabular}{|c|c|c|c|}
\hline $\begin{array}{l}\text { T1: few seconds } \\
\text { T2: few seconds } \\
\text { T3: } 5-10 \text { min }\end{array}$ & \multicolumn{3}{|c|}{$\begin{array}{l}\text { Blood sample collection } \\
\text { Animal perfusion } \\
\text { Sample dissection }\end{array}$} \\
\hline & $\mathrm{JJ}$ & $\mathrm{Jj}$ & $\mathrm{jj}$ \\
\hline $\mathrm{P} 9(n)$ & 3 & 6 & 6 \\
\hline $\mathrm{P} 17(n)$ & 6 & 6 & 6 \\
\hline
\end{tabular}

b

\begin{tabular}{|c|c|c|c|c|c|}
\hline \multicolumn{2}{|c|}{ T1: few seconds } & \multicolumn{4}{|c|}{ Blood collection } \\
\hline \multicolumn{2}{|c|}{ T2: few seconds } & \multicolumn{4}{|c|}{$\begin{array}{l}\text { Sulphadimethoxine } \\
(200 \mathrm{mg} / \mathrm{kg}) \\
\text { injection (IP) }\end{array}$} \\
\hline \multicolumn{2}{|c|}{$\begin{array}{l}\mathrm{T}_{1}: \quad 1 \mathrm{~h} \text { later } \\
\mathrm{T}_{1}: 6 \mathrm{~h} \text { later } \\
\mathrm{T}_{6}: 24 \mathrm{~h} \text { later } \\
\mathrm{T}_{24}: 48 \mathrm{~h} \text { later } \\
\mathrm{T}_{42}: 72 \mathrm{~h} \text { later }\end{array}$} & \multicolumn{4}{|c|}{$\begin{array}{l}\text { Animals returned } \\
\text { to mothers }\end{array}$} \\
\hline \multicolumn{2}{|c|}{ T3: few seconds } & \multicolumn{4}{|c|}{ do shation } \\
\hline \multicolumn{2}{|c|}{ T4: few seconc } & \multirow{2}{*}{\multicolumn{4}{|c|}{ Animal anesthesia }} \\
\hline \multicolumn{2}{|c|}{ T4: few seconds } & & & & \\
\hline \multicolumn{2}{|c|}{ T5: 5-10 min } & \multicolumn{4}{|c|}{$\begin{array}{l}\text { Animal perfusion } \\
\text { Sample collection }\end{array}$} \\
\hline $\mathrm{H}$ & 1 & 6 & 24 & 48 & 72 \\
\hline Control $(n)$ & 6 & 6 & 6 & 6 & 6 \\
\hline Treated $(n)$ & 6 & 6 & 6 & 6 & 6 \\
\hline
\end{tabular}

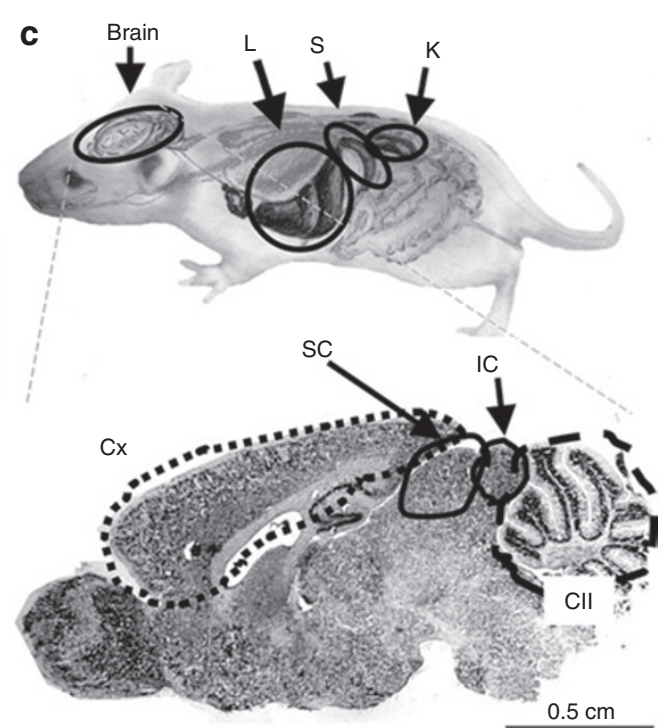

Figure 7. Experimental scheme. (a) Tissue bilirubin in untreated Gunn rat pups. J: wild-type, Jj: heterozygous, and jj: homozygous recessive, hyperbilirubinemic Gunn rats. (b) Tissue bilirubin in Gunn rat pups after exposure to sulphadimethoxine. (c) Drawing of dissected organs/tissues. Cll, cerebellum; CX, cortex; $d$, postnatal age in days; $H$, hours after sulphadimethoxine exposure; IC, inferior colliculi; IP, intraperitoneal; $K$, kidney; $L$, liver; $n$, number of animals used; S, spleen; SC, superior colliculi. Cerebral microsection provided by courtesy of G. Meroni and F. Petrera. 
Table 2. qPCR primer specifications

\begin{tabular}{|c|c|c|c|c|c|}
\hline Gene & $\begin{array}{l}\text { Accession } \\
\text { number }\end{array}$ & Sense & Antisense & $\begin{array}{l}\text { Amplicon } \\
\text { length (bp) }\end{array}$ & $\begin{array}{c}\text { Efficiency } \\
\text { (\%) }\end{array}$ \\
\hline Cyp1a1 & NM_01254.2 & CAGGCGAGAAGGTGGATATGAC & GGTCTGTGTTTCTGACTGAAGTTG & 181 & 91.5 \\
\hline Сур2а3 & NM_007812 & ACACAGGCACCCCAGGACATC & CCAGGCTCAACGGGACAAGAAAC & 99 & 109.2 \\
\hline$A B C \subset 1$ & NM_022281 & ATGGTGTCAGTGGTTTAGG & TGTGGGAAGAAGAGTTGC & 111 & 99.2 \\
\hline Gapdh & NM_017008 & СTCTCTGCTCCTCCСTGTTC & CACCGACCTTCACCATCTTG & 87 & 106 \\
\hline Hprt1 & NM_12583.2 & AGACTGAAGAGCTACTGTAATGAC & GGCTGTACTGCTTGACCAAG & 163 & 94.9 \\
\hline
\end{tabular}

bp, base pairs.

ventricle using a peristaltic pump, until the effluent was visibly free of red cells.

After decapitation, the $\mathrm{Cx}, \mathrm{Cll}, \mathrm{SC}$, and IC were dissected and cleaned of meninges and choroid plexuses as described previously for $\mathrm{Cx}$ (33). In scheme A, the abdominal organs mainly involved in metabolism of bilirubin (liver, spleen, kidney) were also collected (Figure 7c). Each tissue/organ sample was divided into two parts, one for tissue bilirubin quantification and the second one for mRNA extraction followed by qPCR analysis. Samples were immediately stored at $-80^{\circ} \mathrm{C}$ until analysis. All sampling and subsequent analyses were performed under dim light, using foil-wrapped tubes, to minimize bilirubin photooxidation.

\section{Tissue Bilirubin Quantification}

UCB content was determined on rapidly thawed samples using high-performance liquid chromatography with diode array detector (Agilent, Santa Clara, CA) as described (10). Briefly, $300 \mathrm{pmol}$ of mesobilirubin in dimethylsulfoxide (internal standard) was added, and samples were homogenized on ice. Bile pigments were then extracted into chloroform/hexane $(5: 1 \mathrm{vol} / \mathrm{vol})$ at $\mathrm{pH} 6.0$, and contaminants removed by extraction of the pigments in a minimum volume of methanol/sodium carbonate ( $\mathrm{pH} 10)$. The resulting polar droplet was loaded onto a C-8 reverse-phase column (Phenomenex, Torrance, CA), and separated pigments were detected at $440 \mathrm{~nm}$. The concentration of UCB, determined from the area under the curve of the UCB peak in reference to the internal standard of mesobilirubin, was calculated as $\mathrm{nmol} / \mathrm{g}$ of wet tissue weight.

\section{Total Bilirubin and Albumin Determination in Plasma}

After centrifugation (2,500 rpm, $20 \mathrm{~min}$ at room temperature), plasma was collected and immediately frozen at $-20^{\circ} \mathrm{C}$ until assayed. Plasma total bilirubin and albumin were quantified, respectively, by the diazo-reaction (Boehringer-Mannheim Kit 1552414, Monza, Italy) and by the ALB-Plus BCG (Roche Diagnostic, Milan, Italy) kits on an automated Roche-Hitachi analyzer (Roche Diagnostic, Milan, Italy). Samples with hemolysis were discarded.

\section{qPCR Analysis of Cyp and $A B C$ Transcripts}

Total RNA from each region dissected from d17 $\mathrm{jj}$ animals exposed to sulpha or vehicle alone was isolated in TriReagent (Sigma-Aldrich, St Louis, MO) and retro-transcribed $(1 \mu \mathrm{g})$ using the iScript cDNA
Synthesis kit (Bio-Rad Laboratories, Hercules, CA) according to the manufacturer's instructions. Three d17 JJ animals were also injected with sulpha or vehicle to assess a possible direct effect of sulphadimethoxine per se $(1 \mathrm{~h})$ in animals who generate little Bf because of very low serum UCB levels.

Tissue mRNA levels were determined for Cyp1a1, Cyp1a2, Cyp2a3, $A B C c 1$, and $A B C b 1$, and the housekeeping genes (actin; hypoxanthine-guanine phosphoribosyltranferase, Hprt1; and glyceraldehydes 3-phosphate dehydrogenase, Gapdh) (for details see Table 2). The qPCR was performed on $25 \mathrm{ng}$ cDNA with gene-specific sense and antisense primers $(250 \mathrm{nmol} / \mathrm{l}$, all genes) with iQ SYBR Green Supermix in an i-Cycler IQ thermocycler (both from Bio-Rad Laboratories). The thermal cycler conditions consisted of $3 \mathrm{~min}$ at $95^{\circ} \mathrm{C}$ and 40 cycles each at $95^{\circ} \mathrm{C}$ for $20 \mathrm{~s}, 60^{\circ} \mathrm{C}$ for $20 \mathrm{~s}$, and $72^{\circ} \mathrm{C}$ for $30 \mathrm{~s}$. Specificity of the amplification was verified by a melting-curve analysis: nonspecific products of PCR were not found in any case.

The relative quantification was made using Genex software (BioRad Laboratories) based on the $\Delta \Delta \mathrm{Ct}$ method, taking into account the efficiencies of individual genes and normalizing the results to the three housekeeping genes. The levels of mRNA were expressed relative to a selected sample.

\section{Statistical Analysis}

All data are given as means \pm SD. Statistical differences between agematched animals with the same genotype were analyzed using the unpaired, nonparametric, two-tail, Mann-Whitney test. Comparison of different postnatal ages within the same genotype was performed by ANOVA, followed by Tukey-Kramer multiple comparisons test. Differences were considered statistically significant at a $P$ value $<0.05$.

\section{ACKNOWLEDGMENTS}

The authors thank P. Zarattini and A. Lorenzon (CSPA, University of Trieste) for help in the experimental procedure concerning the sulphadimethoxine treatments, J. Donald Ostrow for helpful discussions and critical reading of the manuscript, and G. Meroni and F. Petrera for the cerebral microsection in Figure 7.

\section{STATEMENT OF FINANCIAL SUPPORT}

This work was supported by the Regione Friuli Venezia Giulia (Fondo Regionale FVG LR26/2005), the Telethon grant (GGP10051), the Italian Ministry of Foreign Affairs, Rome, Italy (PhD fellowships to A.L.B., M.C.R., and C.C.Z.) and by the Czech Ministry of Education (2B06155) and the Research Granting Agency of the Czech Republic (CZ:GA CR:P206/11/0836). 


\section{REFERENCES}

1. Benaron DA, Bowen FW. Variation of initial serum bilirubin rise in newborn infants with type of illness. Lancet 1991;338:78-81.

2. Bhutani VK, Johnson L. 2005 Kernicterus: a preventable neonatal brain injury. J Arab Neonatal Forum 2005;2:12-24.

3. Calligaris SD, Bellarosa C, Giraudi P, Wennberg RP, Ostrow JD, Tiribelli C. Cytotoxicity is predicted by unbound and not total bilirubin concentration. Pediatr Res 2007;62:576-80.

4. Takahashi M, Sugiyama K, Shumiya S, Nagase S. Penetration of bilirubin into the brain in albumin-deficient and jaundiced rats (AJR) and Nagase analbuminemic rats (NAR). J Biochem 1984;96:1705-12.

5. Ahlfors CE, Wennberg RP. Bilirubin-albumin binding and neonatal jaundice. Semin Perinatol 2004;28:334-9.

6. Cannon C, Daood MJ, O'Day TL, Watchko JF. Sex-specific regional brain bilirubin content in hyperbilirubinemic Gunn rat pups. Biol Neonate 2006;90:40-5.

7. Aono S, Semba R, Sato H, Kashiwamata S. Mode of bilirubin deposition in the cerebellum of developing jaundiced Gunn rats. Biol Neonate 1989;55:119-23.

8. Daood MJ, Watchko JF. Calculated in vivo free bilirubin levels in the central nervous system of Gunn rat pups. Pediatr Res 2006;60:44-9.

9. Hansen TW. Pioneers in the scientific study of neonatal jaundice and kernicterus. Pediatrics 2000;106:E15.

10. Zelenka J, Lenícek M, Muchová L, et al. Highly sensitive method for quantitative determination of bilirubin in biological fluids and tissues. J Chromatogr B Analyt Technol Biomed Life Sci 2008;867:37-42.

11. Kapitulnik J, Gonzalez FJ. Marked endogenous activation of the CYP1A1 and CYP1A2 genes in the congenitally jaundiced Gunn rat. Mol Pharmacol 1993;43:722-5.

12. De Matteis F, Lord GA, Kee Lim C, Pons N. Bilirubin degradation by uncoupled cytochrome P450. Comparison with a chemical oxidation system and characterization of the products by high-performance liquid chromatography/electrospray ionization mass spectrometry. Rapid Commun Mass Spectrom 2006;20:1209-17.

13. Pons N, Pipino S, De Matteis F. Interaction of polyhalogenated compounds of appropriate configuration with mammalian or bacterial CYP enzymes. Increased bilirubin and uroporphyrinogen oxidation in vitro. Biochem Pharmacol 2003;66:405-14.

14. Abu-Bakar A, Moore MR, Lang MA. Evidence for induced microsomal bilirubin degradation by cytochrome P450 2A5. Biochem Pharmacol 2005;70:1527-35.

15. Hankø E, Tommarello S, Watchko JF, Hansen TW. Administration of drugs known to inhibit P-glycoprotein increases brain bilirubin and alters the regional distribution of bilirubin in rat brain. Pediatr Res 2003;54:441-5.

16. Watchko JF, Daood MJ, Mahmood B, Vats K, Hart C, Ahdab-Barmada M. P-glycoprotein and bilirubin disposition. J Perinatol 2001;21:Suppl 1:S437; discussion S59-62.

17. Corich L, Aranda A, Carrassa L, Bellarosa C, Ostrow JD, Tiribelli C. The cytotoxic effect of unconjugated bilirubin in human neuroblastoma
SH-SY5Y cells is modulated by the expression level of MRP1 but not MDR1. Biochem J 2009;417:305-12.

18. Calligaris S, Cekic D, Roca-Burgos L,et al. Multidrug resistance associated protein 1 protects against bilirubin-induced cytotoxicity. FEBS Lett 2006;580:1355-9.

19. Falcão AS, Bellarosa C, Fernandes A,et al. Role of multidrug resistanceassociated protein 1 expression in the in vitro susceptibility of rat nerve cell to unconjugated bilirubin. Neuroscience 2007;144:878-88.

20. Strauss KA, Robinson DL, Vreman HJ, Puffenberger EG, Hart G, Morton DH. Management of hyperbilirubinemia and prevention of kernicterus in 20 patients with Crigler-Najjar disease. Eur J Pediatr 2006;165: 306-19.

21. Ostrow JD, Pascolo L, Shapiro SM, Tiribelli C. New concepts in bilirubin encephalopathy. Eur J Clin Invest 2003;33:988-97.

22. WatchkoJF.Kernicterusand the molecular mechanisms ofbilirubin-induced CNS injury in newborns. Neuromolecular Med 2006;8:513-29.

23. Chowdhury JR, Kondapalli R, Chowdhury NR. Gunn rat: a model for inherited deficiency of bilirubin glucuronidation. Adv Vet Sci Comp Med 1993;37:149-73.

24. Conlee JW, Shapiro SM. Development of cerebellar hypoplasia in jaundiced Gunn rats: a quantitative light microscopic analysis. Acta Neuropathol 1997;93:450-60.

25. Keino H, Sato H, Semba R, Aono S, Aoki E, Kashiwamata S. Mode of prevention by phototherapy of cerebellar hypoplasia in a new SpragueDawley strain of jaundiced Gunn rats. Pediatr Neurosci 1985;12: 145-50.

26. Schmid R, Hammaker L. Metabolism and disposition of c14-bilirubin in congenital nonhemolytic jaundice. J Clin Invest 1963;42:1720-34.

27. Kapitulnik J, Ostrow JD. Stimulation of bilirubin catabolism in jaundiced Gunn rats by an induced of microsomal mixed-function monooxygenases. Proc Natl Acad Sci USA 1978;75:682-5.

28. Zaccaro C, Sweitzer S, Pipino S, et al. Role of cytochrome P450 $1 \mathrm{~A} 2$ in bilirubin degradation Studies in Cypla2 (-/-) mutant mice. Biochem Pharmacol 2001;61:843-9.

29. Ahlfors CE, Shapiro SM. Auditory brainstem response and unbound bilirubin in jaundiced (jj) Gunn rat pups. Biol Neonate 2001;80:158-62.

30. Gunn $\mathrm{CH}$. Hereditary acholuric jaundice in a new mutant strain of rats. J Hered 1938;29:137-9.

31. Zarattini P, Gazzin S, Stebel M. Improvement of a historical animal model for Crigler Najjar Type I syndrome: development of the normobilirubinemic JJ genotype as a true control for the Gunn jaundiced rat, 2011. Experimental Models: 110-114. (http://www.felasa.eu/media/uploads/ Proceedings_FELASA-ScandLAS-2010_small_SEC.pdf).

32. Gazzin S, Berengeno AL, Strazielle N, et al. Modulation of Mrp1 (ABCc1) and Pgp (ABCb1) by bilirubin at the blood-CSF and blood-brain barriers in the Gunn rat. PLoS ONE 2011;6:e16165.

33. Gazzin S, Strazielle N, Schmitt C,et al. Differential expression of the multidrug resistance-related proteins $\mathrm{ABCb} 1$ and $\mathrm{ABCc} 1$ between blood-brain interfaces. J Comp Neurol 2008;510:497-507. 